\title{
Chromosome 22 Loss of Heterozygosity
}

National Cancer Institute

\section{Source}

National Cancer Institute. Chromosome 22 Loss of Heterozygosity. NCI Thesaurus.

Code C157645.

A molecular abnormality that results in monoallelic loss of function mutations located within chromosome 22. 